\section{RMD Open}

Rheumatic \&

Musculoskeletal Diseases

\title{
Normal salivary gland ultrasonography could rule out the diagnosis of Sjögren's syndrome in anti-SSA-negative patients with sicca syndrome
}

\author{
Omar Al Tabaa (D) ," Hélène Gouze, ${ }^{1}$ Sabrina Hamroun (D) , Elisabeth Bergé, ${ }^{1}$ \\ Rakiba Belkhir, ${ }^{1}$ Stephan Pavy, ${ }^{1}$ Sandrine Jousse-Joulin (D) , ${ }^{2}$ Xavier Mariette ${ }^{1,3}$
}

To cite: Al Tabaa 0, Gouze $\mathrm{H}$, Hamroun S, et al. Normal salivary gland ultrasonography could rule out the diagnosis of Sjögren's syndrome in antiSSA-negative patients with sicca syndrome. RMD Open 2021;7:e001503. doi:10.1136/ rmdopen-2020-001503

- Additional material is published online only. To view please visit the journal online (http://dx.doi.org/10.1136/ rmdopen-2020-001503).

Received 31 October 2020 Revised 7 January 2021 Accepted 14 January 2021

Check for updates

(C) Author(s) (or their employer(s)) 2021. Re-use permitted under CC BY-NC. No commercial re-use. See rights and permissions. Published by BMJ.

${ }^{1}$ Rheumatology, Assistance Publique - Hôpitaux de Paris, Hospital Bicetre, Le KremlinBicetre, France

${ }^{2}$ Rheumatology, University and Regional Hospital Centre Brest, Inserm, LBAI, UMR 1227, Brest, France

${ }^{3}$ Center for Immunology of Viral Infections and Auto-immune Diseases (IMVA), Institut pour la Santé et la Recherche Médicale (INSERM) UMR 1184, Université Paris-Saclay, Le Kremlin Bicêtre France

Correspondence to Professor Xavier Mariette; xavier.mariette@aphp.fr

\section{ABSTRACT}

Objective To evaluate the relevance of salivary gland ultrasound (SGUS) and its place in the diagnostic algorithm in patients referred with dry syndrome (DS) for a suspicion of Sjögren's syndrome (SS).

Methods We included all patients assessed at our dedicated DS clinic from June 2015 to September 2019 for which a SGUS has been carried out. Images were read blindly and the worst salivary gland was scored according to OMERACT classification. Clinical features, disease activity and treatments were collected.

Results 337 patients were seen from June 2015 to September 2019. 269 patients underwent SGUS. 77 patients were diagnosed with SS and 192 did not meet the ACR/EULAR criteria for SS: non-Sjögren's DS (NSDS). Of these 192 patients, 60 had another possible cause of DS, and 132 patients were diagnosed with SAPS (sicca, asthenia, polyalgia syndrome).

SGUS abnormalities were significantly higher in patients with SS versus NSDS: $51 \%$ vs $8 \%$ for a score $\geq 2$ $(p<0.0001)$, and $43 \%$ vs $3 \%$ for a score $\geq 3(p<0.0001)$. SGUS score $\geq 2$ had a specificity (Sp) of $91 \%$, sensitivity (Se) of $57 \%$, positive predictive value (PPV) of $72 \%$ and negative predictive value (NPV) of $82 \%$ for SS diagnosis. SGUS's characteristics in SSA-negative patients were similar to the whole population $(\mathrm{Se}=42 \%, \mathrm{Sp}=91 \%$, $P P V=42 \%, N P V=92 \%)$. The high specificity and NPV in this population could avoid labial salivary gland biopsy (LSGB) in SSA-negative patients with normal SGUS (186 patients, $69 \%)$.

Conclusion SGUS is useful for SS diagnosis. If anti-SSA antibodies are negative and SGUS score $<2$, the diagnosis of SS is very improbable and LSGB could be avoided.

\section{INTRODUCTION}

Sjögren's syndrome (SS) is a heterogeneous systemic disorder potentially involving any organ. ${ }^{2}$ The cornerstone of the disease remains an autoimmune exocrinopathy. ${ }^{3}$ Chronic inflammation and progressive dysfunction of salivary (SG) and lachrymal glands are among the most distinctive lesions of SS.

\section{Key messages}

What is already known about this subject?

- Salivary gland ultrasound (SGUS) is a valuable diagnostic tool for Sjögren's syndrome (SS) diagnosis, but its place in the diagnostic algorithm of SS is not yet established.

What does this study add?

- An abnormal SGUS (score $\geq 2$ ) has a high specificity $(91 \%)$ for the diagnosis of SS in our large population of patients with dry syndrome.

- A normal SGUS has a high negative predictive value for the diagnosis of SS in our large population of patients with dry syndrome, especially in anti-SSAnegative patients $(92 \%)$.

- A SGUS score 3F (3 with fibrosis) is associated with longer duration of the disease and of the sicca symptoms.

How might this impact on clinical practice?

- In case of anti-SSA negativity and normal SGUS, the diagnosis of SS is very improbable and labial salivary gland biopsy could be avoided.

However, some patients complain about dryness (with or without abnormalities on functional tests) without having SS according to the American College of Rheumatology (ACR)/EULAR criteria. For example, many patients with fibromyalgia may suffer from limb pain, fatigue and dryness, the characteristic triad of SS. We have proposed to name this form of fibromyalgia 'sicca, asthenia, polyalgia syndrome' (SAPS). ${ }^{4}$

In clinical practice, it is crucial to be able to distinguish easily both entities since new immunological treatments in development in SS are not adapted to patients with SAPS. This distinction is easy in patients with anti-SSA (Ro), but this antibody is present in only two-thirds of patients with SS. In absence of 
anti-SSA, the diagnosis of SS requires labial salivary gland biopsy (LSGB) that is considered aggressive by some clinicians. Moreover, LSGB interpretation may be not so easy for non-experienced pathologists and also because there is no international consensus of reading.

In the last decade, ultrasonography (US) has been increasingly used in the field of rheumatology. Many researchers and clinicians have identified SG ultrasonography (SGUS) as a valuable diagnostic tool for SS diagnosis. ${ }^{5-10}$ However, probably because it was not evaluated in populations with dryness of different origins, it was not included in the 2016 ACR/EULAR classification criteria.

In 2019, thanks to the OMERACT ultrasound working group, a consensual SGUS score was made ${ }^{11}$ : a novel fourgrade semi-quantitative scoring system for the parotid glands and submandibular glands in patients with SS was defined grade 0, normal parenchyma; grade 1, minimal change: mild inhomogeneity without anechoic/ hypoechoic areas; grade 2, moderate change: moderate inhomogeneity with focal anechoic/hypoechoic areas; and grade 3, severe change: diffuse inhomogeneity with anechoic/hypoechoic areas occupying the entire gland surface. Of note, SG fibrotic lesions were not differentiated in the US scoring used in these studies.

In 2020, Jousse-Joulin et $a l^{12}$ have shown that adding SGUS to the other 2016 ACR/EULAR SS criteria improved the sensitivity from $90.2 \%$ to $95.6 \%$ with a quite similar specificity $(84.1 \%$ vs $82.6 \%)$.

Thus, the aims of this study were to evaluate the relevance of SGUS in a large series of consecutive patients addressed to a tertiary reference centre for suspicion of SS in real-life situation in order to determine its place in the diagnosis algorithm of SS.

\section{MATERIALS AND METHODS \\ Study design}

This was a retrospective, open-label monocentric study following the principles of good clinical practice.

\section{Patient's selection}

In our rheumatology department, a day hospital has been dedicated to patients with dry syndrome (DS) since 2000. For each patient, a clinical (including otorhinopharyngeal and ophthalmological examination), biological evaluation and salivary gland biopsy have been performed. We have included all patients presenting at this day hospital, from June 2015 to September 2019, in whom a SGUS has been performed.

All patients who participated to the dry syndrome day hospital signed a consent form for using their data anonymously for research.

SS diagnosis was made retrospectively according to 2016 ACR/EULAR criteria. All medical files were reviewed to ensure that they met these criteria.

\section{Ultrasonography}

All ultrasound examinations were performed by the same sonographer (Dr Gilles Gailly, in memoriam) in a standardised manner. The ultrasound scanner used was the Arietta V60, Hitachi, with an L64 (18-5 MHz) probe. Two sonographers (OAT and HG) were trained, during a session in December 2019, to read all ultrasound images of the SGs according to the OMERACT classification and the ultrasound images were read blindly by each sonographer. The images were scored according to the OMERACT score. However, in order to differentiate the stage of fibrosis, a fifth grade was added: gland which presents hyperechoic bands that develop into fibrotic tissue indistinguishable from the adjacent soft tissues, we scored it 3F.

Thus, ultrasound images were scored from 0 to 3 (and $3 \mathrm{~F})$ by each sonographer (figure 1). If they disagreed (with the exception of grade $0-1$ ), the images were discussed and a consensus was found. Abnormal SGUS was defined as grade 2,3 or $3 \mathrm{~F}$. In the primary analysis, the SGUS score was the worst grade in one among the four major salivary glands. We also realised a sensitivity analysis with the study of the two worst glands, as suggested by OMERACT. ${ }^{11}$

\section{Data collected}

In addition to SGUS, we collected information on demographics, disease duration, dry syndrome, disease activity parameters (eg, EULAR Sjögren's syndrome disease activity index (ESSDAI) and patient-reported index (ESSPRI) ) and treatments.

\section{Statistical analysis}

To compare characteristics of patients, a univariate analysis was performed by Student t-test (for continuous variables) or $\chi^{2}$ test (for binary variables). To evaluate the SGUS performance, a logistic regression model was used and a receiver operating characteristic (ROC) curve was performed. For all these analyses, the software R (R Core Team 2017) was used.

\section{RESULTS}

In total, 269/337 patients seen at our day hospital from June 2015 to September 2019 underwent a SGUS. Seventy-seven patients had a diagnosis of SS (75 primary and 2 secondary) and 192 did not meet the ACR/EULAR criteria for SS (grouped as non-Sjögren's dry syndrome (NSDS)). Of these 192 patients, 60 had another possible cause of sicca syndrome and 132 patients were diagnosed with SAPS (figure 2).

The kappa concordance coefficient between the two sonographers was $78 \%$ for the parotid glands and $81 \%$ for the submandibular glands. Among 1079 analysed images, there were $152(14 \%)$ discrepancies between the 2 readers on normal (SGUS score $<2$ ) versus abnormal (SGUS score $\geq 2$ ) SGUS status. SGUS was read again by both and a consensus was reached (normal 91\%, abnormal 9\%).

Demographic characteristics were comparable between patients with SS and those with NSDS (table 1). As expected, there was less frequent use of dry mouth 
A

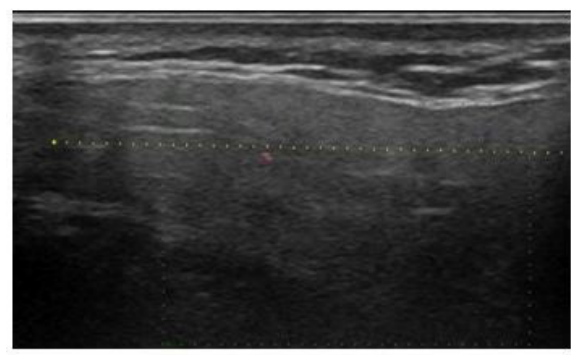

C

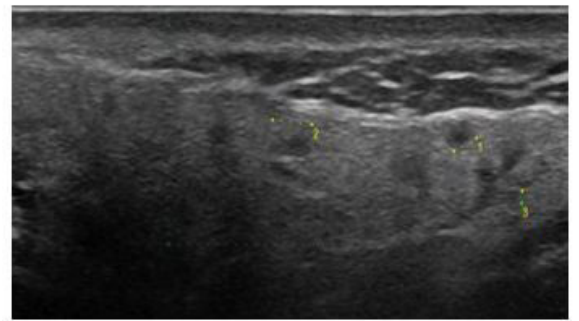

B

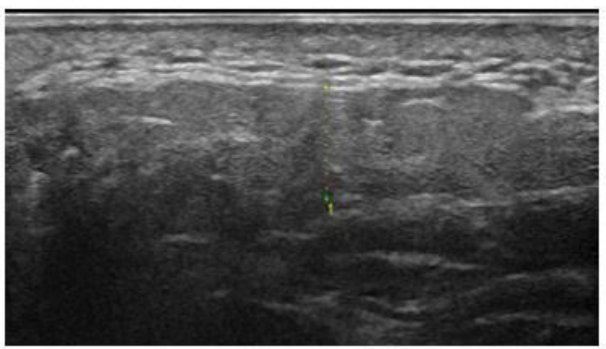

D

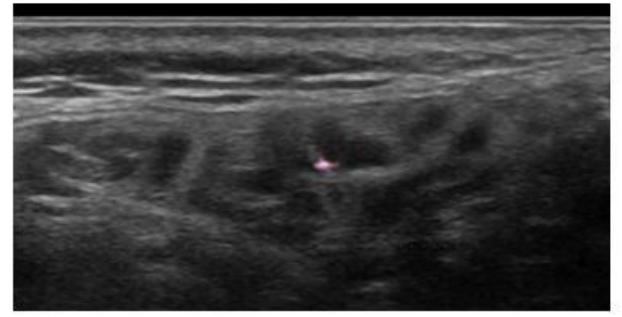

$\mathbf{E}$

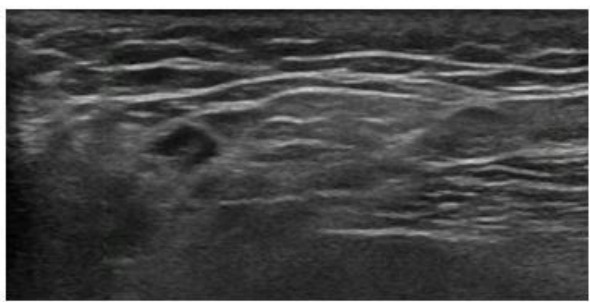

Figure 1 SGUS scoring, according to the OMERACT score. (A) Grade 0, normal parenchyma. (B) Grade 1, minimal change: mild inhomogeneity without anechoic/hypoechoic areas. (C) Grade 2, moderate change: moderate inhomogeneity with focal anechoic/hypoechoic areas but surrounded with normal tissue. (D) Grade 3, severe change: diffuse inhomogeneity with anechoic/hypoechoic areas occupying the entire gland surface but surrounded with no normal tissue. (E) Grade 3F, parotid gland presents hyperechoic bands that develop into fibrotic tissue indistinguishable from the adjacent soft tissues.

treatment $(17 \%$ vs $32, \mathrm{p}=0.02)$, more previous parotid swelling episodes $(34 \%$ vs $10 \%, \quad \mathrm{p}<0.0001)$, more frequently objective xerostomia, verified by unstimulated salivary flow rate test $(52 \%$ vs $31 \%, \mathrm{p}=0.002)$ or eye sicca syndrome $(79 \%$ vs $53 \%, \mathrm{p}<0.001)$, and immunology was more often positive (ANA $78 \%$ vs $35 \%, \mathrm{p}<0.0001$; SSA $65 \%$ vs $2 \%, \mathrm{p}<0.0001)$ in patients with SS than in those with NSDS. Only few patients with SS had a systemic involvement of SS (only two patients with ESSDAI $\geq 5$ ). We also compared the clinical and SGUS characteristics between the three groups SS, SAPS and other causes of DS (online supplemental table S1): the results were similar between these groups, as SS versus NSDS.

Among patients with SS, there was no difference in clinical or biological characteristics between patients with SGUS 3 and $3 F$, but the disease duration was much longer in patients with SGUS score 3F (12.6 years vs 3.6, $\mathrm{p}=0.002$ ) as well as the sicca symptom duration (9.8 years vs 3.6, $\mathrm{p}=0.04$ ) (table 2). The frequency of abnormal SGUS was significantly higher in patients with SS compared with patients with NSDS: $51 \%$ vs $8 \%$ for $\mathrm{a} \geq 2$ score $(\mathrm{p}<0.0001)$, and $43 \%$ vs $3 \%$ for a $\geq 3$ score $(\mathrm{p}<0.0001)$.

SGUS showed a high specificity (Sp) and negative predictive value (NPV) in our population (table 3). For a SGUS score $\geq 2$, the sensitivity (Se) was $57 \%$, Sp $92 \%$, positive predictive value (PPV) $72 \%$ and NPV $82 \%$ (table 3). Sp was higher for a SGUS score $\geq 3$ despite a lower sensitivity and NPV (49\% and $81 \%)$. However, the ROC curves of the couple SGUS-SSA (AUC 0.85, 95\% CI 0.8 to 0.9 ) or SGUS-focus score (AUC $0.86,95 \%$ CI 0.81 to 0.91 ) were not very different than SSA alone (AUC $0.82,95 \%$ CI 0.76 to 0.88 ) or focus score alone (AUC $0.85,95 \%$ CI 0.79 to 0.9 ) (figure 3 ).

There was a good correlation between SGUS and the focus score $(\mathrm{R}=0.5, \mathrm{p}<0.0001)$. Concordance between abnormal SGUS score and positive focus score was of $83 \%$. Cohen's kappa agreement was of 0.48 . Thus, we tried to evaluate if SGUS could replace lip biopsy in a situation where LSGB is mandatory for the diagnosis in anti-SSA-negative patients. In this population of 


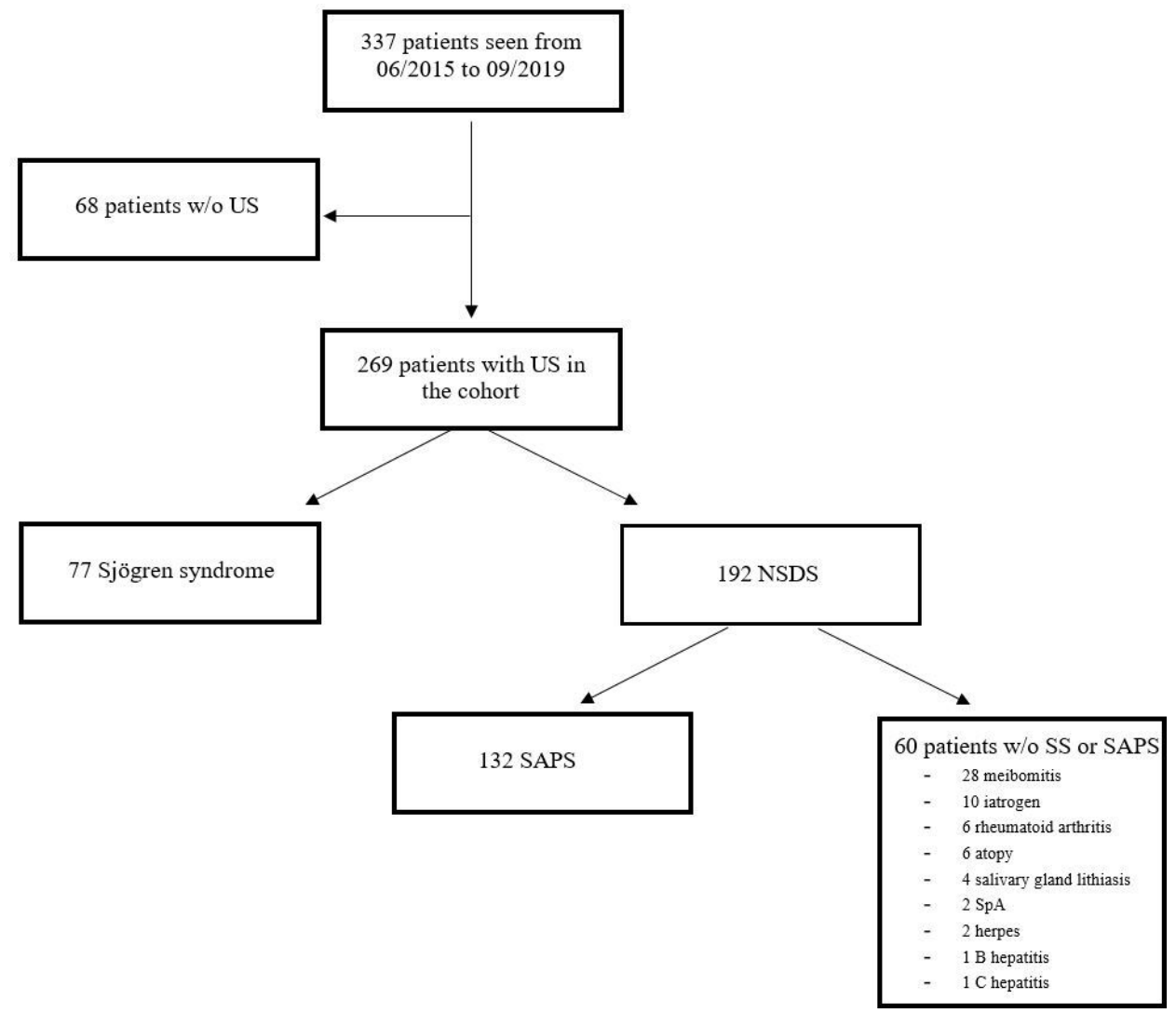

Figure 2 Flow chart of the study. NSDS, non-Sjögren's dry syndrome; SAPS, sicca asthenia polyalgia syndrome; w/o, without.

anti-SSA-negative patients, the ability of a normal SGUS (grade 0 or 1 ) for eliminating the diagnosis of SS was the same as in the whole population (Se $42 \%$, Sp $91 \%$, PPV 42\%, NPV 92\%) (table 3). Interestingly, the population of anti-SSA-negative patients with normal SGUS represents 186 patients in our total population attending our day care unit for suspicion of pSS $(69 \%)$.

Finally, we carried out the same analyses, taking into account the two worst SGUS-scored salivary glands, as proposed by the OMERACT group. The results were very similar (online supplemental table S2): the frequency of abnormal SGUS was significantly higher in patients with SS compared with patients with NSDS ( $44 \%$ vs $5 \%$ for a $\geq 2$ score $(\mathrm{p}<0.0001), 40 \%$ vs $2 \%$ for $\mathrm{a} \geq 3$ score $(\mathrm{p}<0.0001))$. For a SGUS score $\geq 2$, Se was $51 \%$, Sp 96\%, PPV $79 \%$ and NPV $81 \%$ (online supplemental figure 1, online supplemental table S3). In SSA-negative patients, for a SGUS score $\geq 2$, Sp and NPV were similar as in the whole population, even better ( $95 \%$ and $91 \%$, respectively).

\section{DISCUSSION}

This study showed that SGUS could have a place in SS algorithm diagnosis. In our cohort, a SGUS score $\geq 2$ had a sensitivity of $57 \%$ with specificity and NPV of $91 \%$ and $82 \%$, respectively, for the diagnosis of SS in our large population of patients with dry syndrome. The most important finding of our study is that SGUS had the same high specificity and even better NPV values in
anti-SSA-negative patients (91\% and $92 \%$, respectively). This strategy would avoid two-thirds of LSGB in our population. However, it is important to underline that NPVs and PPVs depend on the prevalence of the disease in the investigated population. Moreover, LSGB is important for the diagnosis of SS but also as a predictive factor of evolution. For example, high focus score or presence of ectopic germinal centres are predictive of lymphoma occurrence. Our results do not support not doing LSGB in patients with SS. They just suggest avoiding biopsy in patients with sicca symptoms and with a negative anti-SSA test, in whom the probability that the biopsy could lead to a diagnosis of SS is very low.

We proposed a fifth stage in the OMERACT scoring (score $3 \mathrm{~F}$ ). This stage was already part of the stage 3 OMERACT classification (eg, heterogeneous gland with complete destruction of the parenchyma either with hypo/anechoic areas and with or without fibrous deposits). Nevertheless, it could be useful to differentiate between the two stages since fibrosis might be important (eg, as a predictive factor of efficacy of treatment). Interestingly, patients with score $3 \mathrm{~F}$ had a longer disease duration compared with patients with a SGUS score at 3 . This new $3 \mathrm{~F}$ grade needs to be validated by further independent studies.

Other studies have analysed the place of SGUS in the SS diagnosis criteria: in 1992, De Vita et al ${ }^{13}$ comparatively investigated SGUS abnormalities in patients with 
Table 1 Patients' characteristics

\begin{tabular}{|c|c|c|c|}
\hline & sS $(\mathrm{N}=77)$ & NSDS ( $N=192)$ & $\begin{array}{l}\text { P value (SS } \\
\text { vs others) }\end{array}$ \\
\hline Age (years), mean (SD) & 55 (14.3) & $55.5(14.9)$ & 0.8 \\
\hline Gender (women), n (\%) & $69(90)$ & $172(90)$ & 0.45 \\
\hline Sicca syndrome duration (years), mean (SD) & $4.9(5.2)$ & $6.2(6.3)$ & 0.09 \\
\hline Tobacco consumption, n (\%) & $25(33)$ & $68(35)$ & 0.75 \\
\hline Personal history of autoimmune disease, $\mathrm{n}(\%)$ & $15(20)$ & $34(18)$ & 0.87 \\
\hline Familial history of autoimmune disease, n (\%) & $14(18)$ & $41(21)$ & 0.7 \\
\hline Use of dry mouth treatment, $\mathrm{n}(\%)$ & $13(17)$ & $61(32)$ & 0.02 \\
\hline Body mass index $\left(\mathrm{kg} / \mathrm{m}^{2}\right)$, mean (SD) & $25.4(5.7)$ & $24.2(4.6)$ & 0.09 \\
\hline Raynaud phenomenon, n (\%) & $20(26)$ & $40(22)$ & 0.45 \\
\hline Arthralgia, n (\%) & $53(69)$ & $141(73)$ & 0.54 \\
\hline Previous history of lymphoma, $n(\%)$ & $2(3)$ & $1(<0.1)$ & 0.41 \\
\hline Parotitis, n (\%) & $26(34)$ & $19(10)$ & $<0.0001$ \\
\hline Objective buccal sicca syndrome*, n (\%) & $40(52)$ & $59(31)$ & 0.002 \\
\hline Objective eye sicca syndrome,$+ \mathrm{n}(\%)$ & $61(79)$ & $102(53)$ & $<0.001$ \\
\hline ESSPRI, (0-100) mean (SD) & $58(21)$ & I & I \\
\hline ESSDAI $\geq 5, \mathrm{n}(\%)$ & $2(2)$ & / & / \\
\hline ANA positivity, $\mathrm{n}(\%)$ & $60(78)$ & $67(35)$ & $<0.0001$ \\
\hline SSA positivity, n (\%) & $50(65)$ & $4(2)$ & $<0.0001$ \\
\hline SSB positivity, n (\%) & $20(26)$ & $3(2)$ & $<0.0001$ \\
\hline RF positivity, n (\%) & $26(34)$ & $14(7)$ & $<0.0001$ \\
\hline ACPA positivity, $n(\%)$ & $6(8)$ & $7(3.6)$ & 0.26 \\
\hline C3 (g/L), mean (SD) & $1.1(0.2)$ & $1.1(0.2)$ & 0.30 \\
\hline C4 (g/L), mean (SD) & $0.2(0.1)$ & $0.3(0.2)$ & 0.009 \\
\hline $\operatorname{lgG}(\mathrm{g} / \mathrm{L})$, mean (SD) & $14.6(4.7)$ & $10.9 \pm 3$ & $<0.0001$ \\
\hline Chisholm $\geq 3, \mathrm{n}(\%)$ & $53(69)$ & $4(2.1)$ & $<0.0001$ \\
\hline Focus score $\geq 1, \mathrm{n}(\%)$ & 49/72 (68) & $4(2.1)$ & $<0.0001$ \\
\hline \multicolumn{4}{|l|}{ US scores } \\
\hline Score 0, n (\%) & $22(29)$ & $67(56)$ & $<0.0001$ \\
\hline Score 1, n (\%) & $16(21)$ & $46(38)$ & 0.02 \\
\hline Score 2, n (\%) & $6(8)$ & $6(5)$ & 0.6 \\
\hline Score 3 and $3 F, n(\%)$ & $33(43)$ & $1(1)$ & $<0.0001$ \\
\hline
\end{tabular}

${ }^{*}$ Objectified by unstimulated salivary flow rate test.

†Objectified by Schirmer's test.

ANA, anti-nuclear antibodies; NSDS, non-Sjögren's dry syndrome; RF, rheumatoid factor; SS, Sjögren's syndrome; US, ultrasonography.

SS and controls. Scores of $0 \pm 3$ were assigned to each pair of glands according to inhomogeneity, hypoechogenicity, size, and posterior borders of the parotid and submandibular glands, and this scoring system showed a sensitivity of $88.8 \%$ and a specificity of $84.6 \%$ for SS. Zhou et al realised a meta-analysis to evaluate the diagnostic accuracy of SGUS and observed a sensitivity of $75 \%$ and specificity of $93 \%$ for the diagnosis of SS. ${ }^{14}$ Nevertheless, they pulled studies with different scoring systems. Recently, Mossel et al have shown that a combination of parotid and submandibular gland US grading and a serological test for anti-SS antibodies can effectively predict the AECG, ACR or ACR/EULAR classification results of patients. ${ }^{15}$
The authors reported that the absolute agreement of US results was at most moderate compared with an AECG (82\%), ACR $(86 \%)$ or ACR/EULAR $(80 \%)$ based classification, as well as with LSGB $(79 \%)$ results. In the study of Lee $e t a l,{ }^{16}$ using a SGUS 0-48 scoring system, a SGUS cut-off of $\geq 14$ had a sensitivity of $80.9 \%$ and a specificity of $95.5 \%$ for the diagnosis of SS (for AECG criteria). Lastly, in 2020, Jousse-Joulin et $^{1 l^{12}}$ showed that SGUS had similar weight compared with minor items and its addition improves the performance of the 2016 ACR/EULAR classification criteria.

Our main analysis was based on the worst salivary gland for the SGUS scoring. According to the OMERACT, the 
Table 2 Univariate analysis comparing patients characteristics with SGUS scoring 3 and $3 F$ in SS population

\begin{tabular}{|c|c|c|c|}
\hline & $3(\mathrm{~N}=24)$ & $3 F(N=9)$ & $P$ value \\
\hline $\begin{array}{l}\text { Age (years), mean } \\
\text { (SD) }\end{array}$ & $51(15)$ & $59(13)$ & 0.14 \\
\hline $\begin{array}{l}\text { Gender (women), n } \\
(\%)\end{array}$ & $20(87)$ & $8(89)$ & 1 \\
\hline $\begin{array}{l}\text { Sicca syndrome } \\
\text { duration (years), } \\
\text { mean (SD) }\end{array}$ & $3.6(3.6)$ & $9.8(7.6)$ & 0.04 \\
\hline $\begin{array}{l}\text { Disease duration } \\
\text { (years), mean (SD) }\end{array}$ & $3.6(3.4)$ & $12.1(8.3)$ & 0.002 \\
\hline $\begin{array}{l}\text { Body mass index }(\mathrm{kg} / \\
\left.\mathrm{cm}^{2}\right) \text {, mean }(\mathrm{SD})\end{array}$ & $25.6(6.5)$ & $23.5(4.1)$ & 0.29 \\
\hline Parotitis, n (\%) & $16(67)$ & 3 (33) & 0.12 \\
\hline SSA positivity, n (\%) & $17(71)$ & 8 (89) & 0.3 \\
\hline $\begin{array}{l}\text { Focus score, mean } \\
\text { (SD) }\end{array}$ & $2.1(1.4)$ & $1.8(1.3)$ & 0.57 \\
\hline $\begin{array}{l}\text { Focus score } \geq 1, n \\
(\%)\end{array}$ & $19(79)$ & $6(67)$ & 0.37 \\
\hline ESSDAI, mean (SD) & $2.6(1.5)$ & $2.3(2)$ & 0.74 \\
\hline $\begin{array}{l}\text { ESSPRI, (0-100) } \\
\text { mean (SD) }\end{array}$ & $49.9(22.9)$ & 46.3 (7.9) & 0.51 \\
\hline
\end{tabular}

ESSDAI, EULAR Sjögren's syndrome disease activity index; ESSPRI, EULAR Sjögren's syndrome patient-reported index; SGUS, salivary gland ultrasound; SS, Sjögren's syndrome.

ultrasound scoring should be done on the two worst glands. The analysis on two glands yielded very similar results as on one gland. Thus, our results may suggest that the OMERACT recommendations could be simplified in the future. Of course, analysis of only one gland could be advised only in case of involvement of the four glands in a context of sicca syndrome and this will need further independent validation.

This study has some limitations. Our SS population was comparablewith other studies. ${ }^{10}{ }^{17-19}$ However, few patients had a systemic involvement of SS $(2 \%$ with ESSDAI $\geq 5$ ). This retrospective study was conducted in a single tertiary care centre and it will be important to

Table 3 Characteristics of SGUS score in the whole cohort and in SSA-negative patients

\begin{tabular}{llllll}
\hline & $\begin{array}{l}\text { SGUS } \\
\text { score }\end{array}$ & $\begin{array}{l}\text { Se } \\
\text { (\%) }\end{array}$ & $\begin{array}{l}\text { Sp } \\
\text { (\%) }\end{array}$ & $\begin{array}{l}\text { PPV } \\
\text { (\%) }\end{array}$ & $\begin{array}{l}\text { NPV } \\
\text { (\%) }\end{array}$ \\
\hline Whole cohort & $\geq 2$ & 57 & 92 & 72 & 82 \\
$\mathrm{~N}=269$ & $\geq 3$ & 49 & 97 & 87 & 81 \\
& $3 \mathrm{~F}$ & 14 & 99 & 82 & 74 \\
$\begin{array}{l}\text { Anti-SSA-negative } \\
\text { patients }\end{array}$ & $\geq 2$ & 41 & 91 & 42 & 92 \\
$\mathrm{~N}=215$ & & & & & \\
\hline
\end{tabular}

NPV, negative predictive value; PPV, positive predictive value; Se, sensitivity; SGUS, salivary gland ultrasound; Sp, specificity.

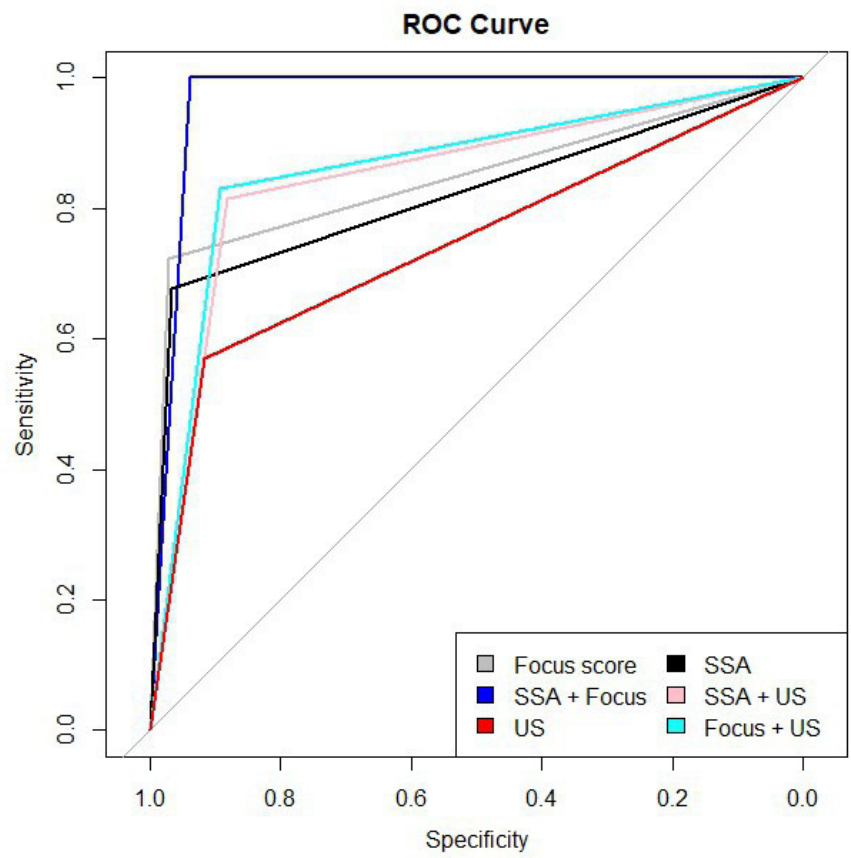

Figure 3 Receiver operating characteristic (ROC) curve for Sjögren's syndrome diagnosis. Ultrasonography (US) score $\geq 2$ on the worst gland as cut-off value. Sensitivity/specificity: (1) Focus score: $72.3 \% / 97.2 \%$ (area under the curve (AUC): $0.85,95 \% \mathrm{Cl} 0.79$ to 0.9 ). (2) SSA : $67.7 \% / 96.7 \%$ (AUC: 0.82 , $95 \% \mathrm{Cl} 0.76$ to 0.88 ). (3) SSA+focus score: $100 \% / 93.9 \%$ (AUC: 0.97 95\% Cl 0.95 to 0.99). (4) US: 56.9\%/91.6\% (AUC: $0.74,95 \% \mathrm{CI} 0.68$ to 0.81 ). (5) US+SSA: $81.5 \% / 88.3 \%$ (AUC: $0.85,95 \% \mathrm{Cl} 0.8$ to 0.9 ). (6) US+focus score: $83.1 \% / 89.4 \%$ (AUC: $0.86,95 \% \mathrm{Cl} 0.81$ to 0.91 ).

confirm that it is generalisable. We realised a unique SGUS and we did have a longitudinal follow-up.

It also has some important strengths. We systematically collected parameters for the diagnosis and for evaluating the disease activity and patient-related outcomes in all patients. In addition, all ultrasound examinations were performed by the same operator in a standardised manner. Unlike Jousse-Joulin et $a l^{11}$ who made video clips in order to analyse the ultrasound anomalies, we had numerous sections of the salivary glands for a pertinent analysis. Moreover, two sonographers were trained to read ultrasound images of the SGs according to the OMERACT classification and the ultrasound images were read blindly by each sonographer. The kappa concordance coefficient was slightly higher in our study than in the literature. Indeed, in another study, Jousse-Joulin et al reported that interobserver agreements were fair to substantial ( $\kappa$-values $=0.32$ to 0.74$).{ }^{20}$

In conclusion, our study suggests that SGUS is a useful tool for SS diagnosis and may be performed before a LSGB. If anti-SSA antibodies are negative and SGUS score is inferior at 2 (which represents two-thirds of our population), the diagnosis of SS is very improbable and LSGB could be avoided. However, in case of negativity of anti-SSA and abnormal SGUS, LSGB must be carried 
out. In this regard, further studies to evaluate the place of SGUS in the diagnostic algorithm of SS are necessary.

Acknowledgements This article is dedicated to the memory of Dr Gilles Gailly, who performed all the ultrasound examination.

Contributors OAT: collected data, read the ultrasonography images, wrote the article. HG: collected data, did the statistics, read the ultrasonography images. SH: collected data, wrote the article. EB: collected data. RB: revised the manuscript. SP: revised the manuscript. SJ-J: supervised and participated in writing. XM: supervised and participated in writing.

Funding The authors have not declared a specific grant for this research from any funding agency in the public, commercial or not-for-profit sectors.

Competing interests None declared.

Patient consent for publication Not required.

Provenance and peer review Not commissioned; externally peer reviewed.

Data availability statement All data relevant to the study are included in the article or uploaded as online supplemental information.

Open access This is an open access article distributed in accordance with the Creative Commons Attribution Non Commercial (CC BY-NC 4.0) license, which permits others to distribute, remix, adapt, build upon this work non-commercially, and license their derivative works on different terms, provided the original work is properly cited, appropriate credit is given, any changes made indicated, and the use is non-commercial. See: http://creativecommons.org/licenses/by-nc/4.0/.

ORCID iDs

Omar Al Tabaa http://orcid.org/0000-0002-9327-7169

Sabrina Hamroun http://orcid.org/0000-0003-2721-1249

Sandrine Jousse-Joulin http://orcid.org/0000-0002-5479-5887

\section{REFERENCES}

1 Brito-Zerón P, Baldini C, Bootsma H, et al. Sjögren syndrome. Nat Rev Dis Primers 2016;2:16047.

2 Mariette X, Criswell LA. Primary Sjögren's syndrome. N Engl J Med 2018;378:931-9.

3 Skopouli FN, Moutsopoulos HM. Autoimmune epitheliitis: Sjögren's syndrome. Clin Exp Rheumatol 1994;12 Suppl 11:S9-11.

4 Mariette X, Caudmont C, Berge E, et al. Dry eyes and mouth syndrome or sicca, asthenia and polyalgia syndrome? Rheumatology 2003;42:914-5.

5 Baldini C, Luciano N, Tarantini G, et al. Salivary gland ultrasonography: a highly specific tool for the early diagnosis of primary Sjögren's syndrome. Arthritis Res Ther 2015;17:146.

6 Wernicke D, Hess H, Gromnica-Ihle E, et al. Ultrasonography of salivary glands - a highly specific imaging procedure for diagnosis of Sjögren's syndrome. J Rheumatol 2008;35:285-93.
7 Jousse-Joulin S, Milic V, Jonsson MV, et al. Is salivary gland ultrasonography a useful tool in Sjögren's syndrome? A systematic review. Rheumatology 2016;55:789-800.

8 Le Goff M, Cornec D, Jousse-Joulin S, et al. Comparison of 2002 AECG and 2016 ACR/EULAR classification criteria and added value of salivary gland ultrasonography in a patient cohort with suspected primary Sjögren's syndrome. Arthritis Res Ther 2017; 19:269.

9 Zabotti A, Zandonella Callegher S, Gandolfo S, et al. Hyperechoic bands detected by salivary gland ultrasonography are related to salivary impairment in established Sjögren's syndrome. Clin Exp Rheumatol 2019;37 Suppl 118:146-52.

10 Fidelix T, Czapkowski A, Azjen S, et al. Salivary gland ultrasonography as a predictor of clinical activity in Sjögren's syndrome. PLoS One 2017;12:e0182287.

11 Jousse-Joulin S, D'Agostino MA, Nicolas C, et al. Video clip assessment of a salivary gland ultrasound scoring system in Sjögren's syndrome using consensual definitions: an OMERACT ultrasound working group reliability exercise. Ann Rheum Dis 2019;78:967-73.

12 Jousse-Joulin S, Gatineau F, Baldini C, et al. Weight of salivary gland ultrasonography compared to other items of the 2016 ACR/EULAR classification criteria for primary Sjögren's syndrome. J Intern Med 2020;287:180-8.

13 De Vita S, Lorenzon G, Rossi G, et al. Salivary gland echography in primary and secondary Sjögren's syndrome. Clin Exp Rheumatol. In Press 1992;10:351-6.

14 Zhou M, Song S, Wu S, et al. Diagnostic accuracy of salivary gland ultrasonography with different scoring systems in Sjögren's syndrome: a systematic review and meta-analysis. Sci Rep 2018;8:17128.

15 Mossel E, Delli K, van Nimwegen JF, et al. Ultrasonography of major salivary glands compared with parotid and labial gland biopsy and classification criteria in patients with clinically suspected primary Sjögren's syndrome. Ann Rheum Dis 2017;76:1883-9.

16 Lee K-A, Lee S-H, Kim H-R. Diagnostic and predictive evaluation using salivary gland ultrasonography in primary Sjögren's syndrome. Clin Exp Rheumatol 2018;36:165-72.

17 Theander E, Mandl T. Primary Sjögren's syndrome: diagnostic and prognostic value of salivary gland ultrasonography using a simplified scoring system: simplified ultrasound scoring for primary SS salivary glands. Arthritis Care Res 2014;66:1102-7.

18 Inanc N, Sahinkaya Y, Mumcu G. Evaluation of salivary gland ultrasonography in primary Sjögren's syndrome: does it reflect clinical activity and outcome of the disease?. Clin Exp Rheumatol 2019;37:S140-5

19 Hammenfors DS, Brun JG, Jonsson R, et al. Diagnostic utility of major salivary gland ultrasonography in primary Sjögren's syndrome. Clin Exp Rheumatol 2015;33:56-62.

20 Jousse-Joulin S, Nowak E, Cornec D, et al. Salivary gland ultrasound abnormalities in primary Sjögren's syndrome: consensual US-SG core items definition and reliability. RMD Open 2017;3:e000364. 